\title{
Application of Gold Ore Tailings (GOT) as a source of micronutrients for the growth of plants
}

\author{
Swaroop G*, Keshav A Bulbule, P Parthasarathy, Yogesh Shivakumar, Ranjith Muniswamy, \\ Reshma Annamati, Priyanka D \\ MS (Medicinal Chemistry), Newcastle University, United Kingdom \& PhD Scholar (Medical Oncology), International University for \\ Complementary Medicine, Colombo \\ Professor, Department of Chemistry, K.L.E's S. Nijalingappa College \\ Managing Director, E-Parisaraa, Dabaspet, Bangalore \\ PhD Scholar (Molecular Medicine), University of Eastern Piedmont Amedeo Avagadro, Italy \\ PhD Scholar (Molecular Medicine), University of Eastern Piedmont Amedeo Avagadro, Italy \\ PhD Scholar (Medical Oncology), International University for Complementary Medicine, Colombo \\ *Corresponding authors E-mail: simhavahini23@gmail.com / kabulbule@gmail.com
}

\begin{abstract}
Plants require sixteen nutrients that include both macro and micronutrients. Along with macronutrients N, P, K, micronutrients $\mathrm{Cu}, \mathrm{Fe}, \mathrm{Mn}, \mathrm{Zn}, \mathrm{S}$ etc., play a vital role not only for the healthy growth of the plants but also in the increased yield of the produce. Many factors like the quality and composition of the soil, the types of the fertilizers used and supply of micronutrients decide the growth of the plant and the yield of the commercial crops. It is an established fact that Mining wastes all over the world are found to contain un-extracted metals and non-metals present in the residue. Such residues are known as Ore Tailings and have been used as a best source of micronutrients. Karnataka state is rich in terms of mineral wealth. Hutti Gold Mine of Raichur district of Karnataka state is the leading Gold producer of India. On the lines of COT (Copper Ore Tailings), present research work focuses on the use of GOT (Gold Ore Tailings) as a source of micronutrients. The present innovative research work, once becomes successful will be certainly a boon to the farmers, helps in the judicious use of thousands of tons of GOT as a source of micronutrients and further for the safe disposal of the left over residue in an environment friendly way not only in our country but also elsewhere in the world.
\end{abstract}

Keywords: Brassica oleracea botrytis, Brassica oleracea capitata, Gold ore tailings, Phaseolus aureus.

\section{Introduction}

Micronutrients play a vital role in soil-plant-animal-human environment in reaching the targeted quantity and quality of food to maintain a good health. After green revolution, soils are showing deficiencies of micronutrients due to the low supplementation of exhausted micronutrients either through fertilizers or manures. Out of 2, 48, 786 soil samples analysed from different states for micronutrient status. 48, 12, 5, 2.5, 33, 13 percent of soils were found deficit in $\mathrm{Zn}$, $\mathrm{Fe}, \mathrm{Mn}, \mathrm{Cu}, \mathrm{B}$ and Mo respectively (Singh 1999) [6]. Whereas in Karnataka , out of 52,275 soil samples analyzed all over the state showed 80, 31, 9, 3 \& 25 percent deficiency in $\mathrm{Zn}, \mathrm{Fe}, \mathrm{Mn}, \mathrm{Cu} \& \mathrm{~B}$ respectively (State Dept. of Agricultural report ). To correct the micronutrient deficiency and soils, micronutrient fertilizers and organic manures are widely used. Commercial crops in general, fruit and vegetable crops in particular need regular application of micronutrients to get quality and valued produce. As per the survey report by Ministry of Agriculture, Government of India (1991-92). The consumption of total micronutrient fertilizers in India were 1, 66,225 and 8, 93,437 thousand metric tons respectively [7]. With an increase in deficiencies of micronutrients in soils, the use of micronutrient fertilizers is increasing day by day and so also the cost of these fertilizers. Hence to minimize the cost of input and to meet the demand of use of micronutrient fertilizers. There is a need to go for application of the micronutrient rich agricultural, industrial wastes and mine waste as source of micronutrients to the crops without affecting the soil wealth and environment [8], [9].

Karnataka has abundant minerals / ore like Iron, Manganese, Gold, Chromite, Copper, Limestone, Bauxite etc and it stands fourth as per the mineral resource in the country. After the extraction of element from the mine ore, the left out solid wastes are generally dumped without being used. These solid wastes do contain unextracted and other elements, depending upon the composition of ore. Some of the elements present in the ore wastes are considered as essential plant 
nutrients. There is a need to study the nutrient composition and their solubility in soil and to use these as source of micronutrient to the crops [6].

Main objective of our research is to use the Processed Gold Ore Tailings (P-GOT) as a source of micronutrients for agriculture. Our research aim was to study the influence of micronutrients on the growth of Green gram (Phaseolus aureus), Cauliflower (Brassica oleracea botrytis) and Cabbage (Brassica oleracea capitata) [2], [4]. Study the safe disposal of GOT dumped for decades without being used. To know the nutrient composition, Physiochemical properties of GOT and its solubility in soil. To fix the optimum level of ore waste application to different crops and to know the residual effect of nutrients in soils for the succeeding crops like Onion, Tulip etc. Investigate the heavy metal content and its accumulation in plants.

\section{Materials and methods}

\subsection{GOT}

Hutti Gold Mines Ltd (HGML) in Raichur District of Karnataka is the only leading gold producer in India. The rich grade ore contains about 4-6 g of gold per ton. The ore is available at the depth of 3,000-3,500 feet below the ground level. The ore from deep mines are shifted to the surface is crushed and finely ground to about minus 200 mesh. This, when processed with the use of cyanide yields the precious metal but leaves behind, a huge amount of solid residue called Gold Ore Tailings (GOT). Every day GOT generated has lead about 2000 tons of such huge dump, know left is about one billion tons of GOT. This has not only acquired a vast recleanable land but also causing environmental problems. The extensive joint research work done by the faculty member of Department of Chemistry of K.L.E's S. Nijalingappa College, Bangalore and Surface Chem. Finishers, Peenya, Bangalore on GOT showed that GOT still contained economically recoverable quantity of gold present in it. The continuous "Unmanned Heap Leaching" of GOT carried out yielded 0.60 to $0.80 \mathrm{~g}$ of gold per ton of GOT. The residue now left behind after the recovery of the precious metal from GOT is termed as "Processed GOT". The Cyanide content still associated with the processed GOT is neutralized and then used as the material for the supply of micronutrients for the present research project. Cyanide possibly still associated with processed GOT is scientifically and completely killed and used as basic raw material. The above mentioned researchers provided us the processed GOT and also involved in furthering of the present study. This is the basic raw material for the present research project.

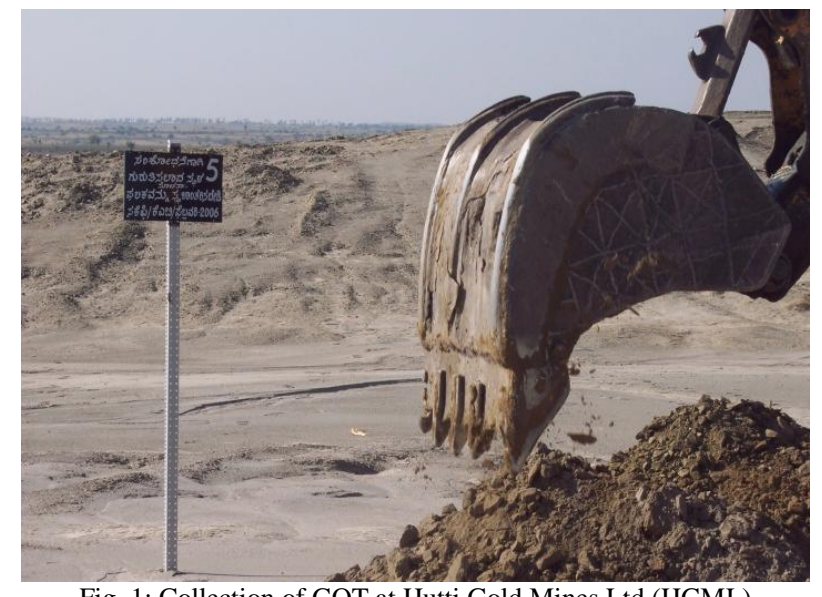

Fig. 1: Collection of GOT at Hutti Gold Mines Ltd (HGML)

Soil: The typical red soil used to cultivate Green gram, Cauliflower and Cabbage by the farmers of Dabaspet area Near Tumkur is used for the present study.

Seeds: Chemically treated seeds were selected for Green gram. Namdhari certified seeds (Export quality) for Cauliflower. Maharani ISI certified seeds for Cabbage.

Water: Under water table was used to irrigate the crops till the cultivation was complete.

The chosen land for study was divided into six strips each measuring 37.4 x 10 foot (420 square foot). Two adjoining strips were identified for each crop. Alternate strip was mixed with GOT by sprinkling in such a way that every square foot of Soil had about $0.5 \mathrm{~kg}$ of GOT. Soil and GOT were thoroughly mixed. Homogeneity of mixture was ensured by ploughing. All the strips were irrigated and later exposed to air for drying. The strips were identified by erecting sign 
boards. First two adjacent strips were identified to grow Green gram, next two for Cauliflower and the last two for Cabbage.

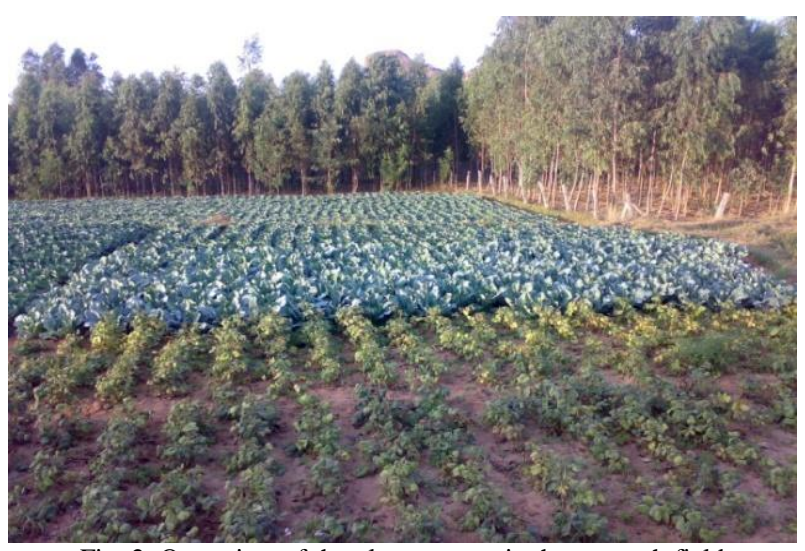

Fig. 2: Over view of the plants grown in the research field

Green gram was cultivated by directly sowing the seeds. Seeds of Cauliflower and Cabbage were sent to Sri Rama Nursery, where the ISI Certified seeds were sown in a Coco-peat. One tray of Coco-peat contains $1 \mathrm{~kg}$ of the coco peat. Before loading the coco-peat, mixture is sterilized at $100^{\circ} \mathrm{C}$ and then loaded to trays. The loaded seed trays are kept in Green House for the germination of saplings for about 25 days. Water sprat is done only once in a day. Saplings of Cauliflower and Cabbage were grown in nursery which later on was replanted in the identified strips.

Periodically plants were irrigated, removal of weeds and other required care like spraying of insecticide was carried out for the crops grown both in Soil and Soil + GOT. Particular Insecticides were used for the crops grown for the present study for the better yield and to prevent invasion of pests. Green gram: Imidacloprid $17.8 \%$, Cauliflower: Success, Cabbage: Parrysulphan 35 EC

Green gram was harvested after about three months, Cauliflower was harvested after two months and Cabbage was harvested after two months.

\subsection{Preparation of land and addition of GOT}

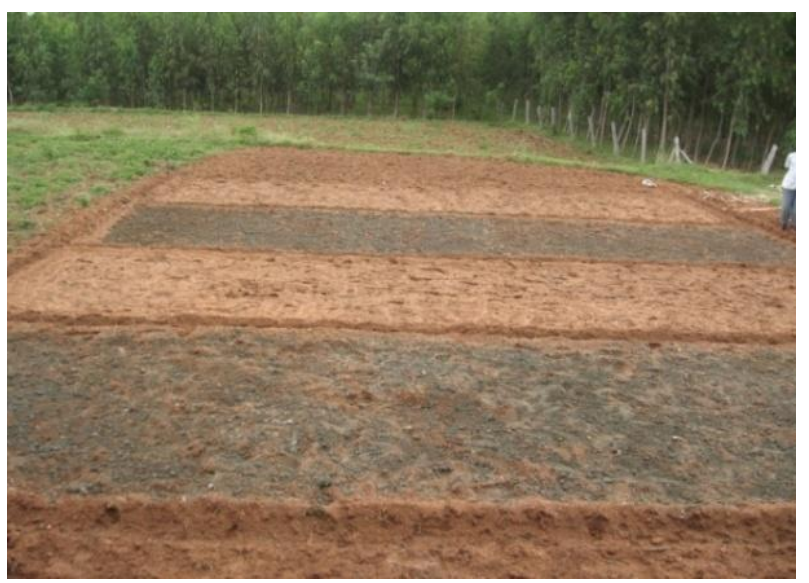

Fig. 3: The land has been sprinkled with 25 kilos of Gold Ore Tailings in the alternate plots.

The method adopted for mixing of ore tailings is "Broadcast mixing". This method is by sprinkling GOT by hand by covering maximum area of the plot. We have used this method in our present study. Recommended level of GOT is to be applied directly or mixing with farm yard manure at the time of land preparation or with fertilize at the time of sowing

\subsection{Study of Nitrogen fixation in Phaseolus aureus by isolation of rhizobium bacteria from root nodules}

Entry of rhizobia into the plant root system is rather peculiar. Studies on Rhizobium provided the first reaction of the root system to the presence of rhizobia is a curling and deformation of root hair. On entering the cortical cells they lodge themselves in the polyploidy cells of nodules called Bacteriods. Bacteriods surrounded by Leghaemoglobin which 
are ready to fix nitrogen and make available ammonium to plants in the form of amino acid. Once this bacteria enters through the root the formation of a thread like structure visible inside the root hair called injection thread. The curling effect has been attributed to production of Indole Acetic Acid (IAA), a hormone produced in the root region by rhizobia. Once the bacterium gains entry into the root system, they divide randomly and become plueromorphic in shape (X, Y, I, V, W). At this point, they are referred to as Bacteriods. Their division of cortical cells, it takes place rapidly and gives rise to a structure called Nodule. Thus rhizobia can be observed in nodules as Bacteriods of various shapes [3].

\subsection{Isolation of bacteroids from root nodules}

Legume root nodule sample are selected and separated from the root end and were washed thoroughly using water. Nodules surface sterilized with $0.1 \%$ of Mercuric Chloride for $5 \mathrm{~min}$ and washed thoroughly with distilled water. They are transferred into 70\% Alcohol for $1 \mathrm{~min}$. The roots are washed with distilled water for 3-4 times. They are then transferred into clean glass slide with a drop of saline and crushed with the help of another slide. Some of the nodules that are crushed are streaked by taking loop-full of inoculum on YEMA. Then plates are incubated at $37^{\circ} \mathrm{C}$ for about 24 hrs. A surface sterilized nodule is crushed between two clean glass slides. The nodule suspension adhering on both the slides is smeared and air dried and heat fixed. The heat fixed slid is subjected to gram's staining technique. It is air dried and observed under microscope [3].

\subsection{Study of extraction and estimation of proteins from Phaseolus aureus}

To extract and estimate the amount of protein present in the Phaseolus aureus grown in presence and absence of GOT in research field by Salt precipitation method.

\subsection{Preparation of plant tissue extract}

Weigh $3 \mathrm{~g}$ of Green gram and grind with $5 \mathrm{~mL}$ of cold distilled water using mortar and pestle. The volume is made up to $15 \mathrm{~mL}$ with cold distilled water. The tissues homogenate was taken in centrifuge tube and centrifuged at $1000 \mathrm{rpm}$ for $5 \mathrm{~min}$ and supernatant was taken. To the collected supernatant $0.8 \mathrm{~g}$ of Ammonium Sulphate is added carefully to produce $45 \%$ saturation. The above solution is allowed to stand on ice for $45 \mathrm{~min}$. The solution is centrifuged at 3000 rpm for $10 \mathrm{~min}$. The precipitate is collected and dissolved in $5 \mathrm{~mL}$ of distilled water [1].

\subsection{Estimation of proteins by Lowry's method}

Pipette out $0.2,0.4,0.6,0.8$ and $1.0 \mathrm{~mL}$ aliquots of standard protein solution $(200 \mu \mathrm{g} / \mathrm{mL})$ to different clean and dry boiling tubes. Make the volume in each case to $1.0 \mathrm{~mL}$ with distilled water. Add $5.0 \mathrm{~mL}$ of alkaline Copper reagent to all the tubes. Mix the solution well and allow the tubes to stand for $10 \mathrm{~min}$. Then add $0.5 \mathrm{~mL}$ of $1: 1$ diluted. Folin-ciochateaus (FC) reagent to each tube and thoroughly mix the contents of each tube using cyclomixer. After keeping the test tubes for rest of about $30 \mathrm{~min}$, read the absorbance at $660 \mathrm{~nm}$ against the blank solution.

\subsection{Sample preparation for analysis of Control soil and Soil + GOT}

Cone and quartering is the method of reducing a gross sample to manageable size while still obtaining a representative sample. After thorough mixing, the material is formed into a cone that is then leveled into a flat circular heap. The heap is then divided diametrically into four equal quarters. Two opposite quarters are discarded and the remaining two opposite quarters are retained and formed into a second cone. The process is repeated until the four equal quarters contain the desired amount of sub sample.

Cone and quartering. The main problem with scoop and thief sampling is that the samples are removed from a static powder bed, and there is simply no effective way to sample a nonmoving powder and obtain a representative sample. One procedure that attempts to address this problem is that of coning and quartering. For this procedure, one begins by pouring a cone of material, which is then flattened as evenly as possible. The material is then divided into quarters, whereupon two opposite quarters are discarded. The remaining two quarters are recombined and poured into another conical pile, which is then flattened and divided. The quartering process is continued until one is left with an amount of material that is the desired sample Great care must be taken when obtaining a sample by coning and quartering. When the initial powder sample is poured, it will undergo the full range of processes that result in segregation of particles according to their relative size. Because their flow ability is the poorest, the finer particles will collect at the center of the cone, and the coarser particles will flow toward the edges of the cone. Hence, each wedge of a poured cone will 
become severely segregated by the act of pouring, making the process of subdivision and recombination critical. It is not unusual to obtain large standard deviations in particle-size results when the coning and quartering method is used to obtain a sample [8].

\subsection{Basic principles, techniques and analytical methods involved in Brassica oleracea botrytis and Brassica oleracea capitata analysis}

\section{Sample drying:}

Initial drying is designed to de-activate rapidly all plant enzymes thereby minimizing weight loss and biochemical changes, and to remove all water from the tissues so that the sample reaches an oven dry state and its weight remains unchanged with revealed drying. The samples may be dried at $65-70^{\circ} \mathrm{C}$ in stainless steel lined hot air oven, which allow adequate circulation of air between samples.

Final drying: initial dried samples are weighed, ground and stored for a period prior to the analysis when these may absorb atmospheric moisture. This necessitates second drying at $70^{\circ} \mathrm{C}$ for $12 \mathrm{hrs} \mathrm{immediately} \mathrm{before} \mathrm{analysis.}$

\section{Grinding and storage:}

Dried samples are ground to reduce field samples to manageable size and this facilitates the preparation of homogeneous sub-samples for chemical analysis. During grinding, care must be taken to ensure that it does not segregate into cores and fine particles. Samples should be stored in clearly labeled, air-tight glass or poly-carbonate containers which can withstand a second drying cycle. This should prevent samples from being infected by insects during storage.

Laboratory analysis:

Standard and reproducible techniques have been used. With the advent of computer linked report generating instrument, improvement in the efficiency and speed of quantitative plant analysis have become possible [5].

\subsection{Determination of total Nitrogen in plant samples}

$50 \mathrm{~g}$ of powdered sample is digested with concentrated $\mathrm{H}_{2} \mathrm{SO}_{4}$ in presence of digestion mixture by heating in a fume chamber. During this process, organic nitrogen gets converted into ammonical. During the process of distillation, Ammonia gas released is trapped in basic acid which is then back titrated with standard acid and nitrogen is calculated [5].

\subsubsection{Digestion of sample using block digester}

Weigh about $0.5 \mathrm{~g}$ of plant sample into digestion tube (depending upon nitrogen level in the sample, the sample weight can be reduced or increased). Add $10 \mathrm{~mL}$ of concentrated Sulphuric acid to the sample that is into the digestion tubes along with $1 \mathrm{gm}$ of catalyst mixture and leave for half an hour.

Keep the tubes into the holes of block digester and put on the electrical switch for heating. When the tubes are heated, the contents in the tube become black in color. On heating, the contents of the tube may start foaming and may raise upto the top of the tubes. The tube can be lifted till the foaming subsides. Then add hydrogen peroxide in small increments $(1 \mathrm{~mL}-2 \mathrm{~mL}$ at a time) to avoid frothing by excessive reaction (if you add more, the contents may come on to your hand and burn). When sufficient hydrogen peroxide $(5 \mathrm{~mL})$ has been added, the contents in the tube become very light or even colorless which indicates that sample is digested.

After cooling the contents of the tube, make up the volume to $100 \mathrm{~mL}$. Take $5 \mathrm{~mL}$ from this $100 \mathrm{~mL}$ and distill it to get the amount of nitrogen in the sample.

\subsubsection{Kjeldahl method of digestion of the sample}

Weigh about $0.5 \mathrm{~g}$ of plant sample into $100 \mathrm{~mL}$ of Kjeldahl flask. Add $1-2 \mathrm{~g}$ of digestion mixture and $20 \mathrm{~mL}$ of Sulphuric acid into the Kjeldahl flask swirl gently so as to mix the sample (to keep contact with sample) and keep for half an hour and then heat it slowly till a light bluish green residue is obtained. Then cool the contents and make up the volume to $100 \mathrm{~mL}$ with distilled water.

\subsubsection{Distillation}

Pipette out $10 \mathrm{~mL}$ of digested sample into micro Kjeldahl distillation unit and add small unit of water $(5 \mathrm{~mL})$. In a conical flask, $10 \mathrm{~mL}$ of $4 \%$ Boric acid solution is taken containing mixed indicator to which the condenser outlet of the flask is dipped. Add about $10 \mathrm{~mL}$ of $40 \%$ Sodium hydroxide to the sample in the distillation flask and distill it by heating. Check for completion of distillation with red litmus paper (if unchanged, it shows that the distillation is complete). Take out the flask containing Boric acid and titrated against standard Sulphuric acid till it becomes pink in color which is the equivalence point. 


\subsubsection{Digestion of sample for other nutrients (except Nitrogen)}

The plant material can be digested in diacid mixture and make up volume to estimate different elements in the plant sample.

\subsubsection{Preparation of diacid mixture}

It is prepared using Nitric acid and Perchloric acid in the ratio of 9:4.

\subsubsection{Procedure for digestion of plant sample}

Weigh about 1-2 g ground leaf or plant material into $100 \mathrm{~mL}$ volumetric flask and add $10 \mathrm{~mL}$ di-acid mixture and leave it in the digestion chamber for at least an hour. Add $5 \mathrm{~mL}$ of Nitric acid for pre-digestion and leave for an hour if required. Now, keep them on hot plate and heat at low temperature till the frothing stops. Then rise the temperature of the hot plate. At higher temperature, the acid fumes disappear or ceases. The contents are further evaporated until the volume is reduced to $3-5 \mathrm{~mL}$ and the content become colorless. After the contents are cooled, make up the volume to $100 \mathrm{~mL}$ with distilled water and filter through What Mann's No.1 filter paper for analysis of different elements in this solution. One can analyze $\mathrm{P}, \mathrm{K}, \mathrm{Ca}, \mathrm{Mg}, \mathrm{S}, \mathrm{Fe}, \mathrm{Mn}, \mathrm{Zn}$ and $\mathrm{Cu}$ (and many more can be analyzed) from this digested sample.

\subsubsection{Phosphorus analysis}

Vanadomolybdate and phosphates react to give yellow color complex in Nitric acid medium. This method is simple and stable. Ammonium molybdate and Ammonium vanadate in $\mathrm{HNO}_{3}$ medium: dissolve $25 \mathrm{~g}$ of Ammonium molybdate in $400 \mathrm{~mL}$ of distilled water. Dissolve $1.25 \mathrm{~g}$ of Ammonium metavanadate in $300 \mathrm{~mL}$ of boiling distilled water. Now add this boiled vanadate solution to the molybdate solution and cool to room temperature. Now add $250 \mathrm{~mL}^{\circ} \mathrm{conc}$. $\mathrm{HNO}_{3}$ to the cooled solution and dilute to $1 \mathrm{Lt}$ finally. Transfer $0,1,2,3,4 \& 5 \mathrm{~mL}$ of above solution through a pipette into $50 \mathrm{~mL}$ volumetric flask to get $0,1,2,3,4 \& 5 \mathrm{ppm}$ of Phosphorus respectively. Add 10mL of Vanado-molybdate reagent to each flask and make up the volume with distilled deionised water; shake thoroughly and keep for 30 min for development of yellow color. This yellow color is measured at $470 \mathrm{~nm}$ in spectrophotometer or colorimeter using blue filter. An aliquot of $5 \mathrm{~mL}$ is pipette out into a $50 \mathrm{~mL}$ volumetric flask. Add $10 \mathrm{~mL}$ of Vanado-molybdate reagent to each flask and make up the volume to $50 \mathrm{~mL}$ using distilled water. Shake well and take reading after 30 min. the yellow color is measured as described. The color is stable for $24 \mathrm{hrs}$ or more. From the standard curve, you can get the concentration of the sample for which you have to read the absorbance.

\subsubsection{Determination of Potassium in plant sample}

100 ppm Potassium: dissolve 1.9069g of AR Potassium chloride $(\mathrm{KCl})$ in 1Lt volumetric flask and make up the volume to give $1000 \mathrm{ppm}$ of Potassium. $100 \mathrm{ppm}$ Potassium for working solution: Take $10 \mathrm{~mL}$ of 1000 ppm Potassium into a $100 \mathrm{~mL}$ volumetric flask and make up the volume to get $100 \mathrm{ppm}$ of Potassium $(0,191 \mathrm{~g}$ of $\mathrm{KCl}$ in $1 \mathrm{Lt}$ gives $100 \mathrm{ppm})$. Take $1 \mathrm{~mL}$ of digested sample and make up to $50 \mathrm{~mL}$ with distilled water feed the sample to flame photometer and record the readings. From the standard curve, the concentration of sample can be known

\subsubsection{Determination of Calcium and Magnesium}

Calcium and Magnesium can be determined by two methods: Versenate method (EDTA method) and Estimation through atomic absorption spectrophotometer (emission mode)

Calcium and Magnesium gets complexed by EDTA. First Ca gets complexed at pH 12 and $\mathrm{Mg}$ at pH 10 afterwards. Ca is estimated by using Mureoxide indicator in presence of Sodium hydroxide. Then $\mathrm{Ca}$ and $\mathrm{Mg}$ are estimated by using Eriochrome black-T indicator in presence of Ammonium chloride-ammonium hydroxide buffer solution.

\subsubsection{Calcium and Magnesium estimation}

Pipette out $5 \mathrm{~mL}$ of di-acid extract into a porcelain basin and about $10 \mathrm{~mL}$ of Ammonium chloride-Ammonium hydroxide buffer solution. Add 2-3 drops Eriochrome black-T indicator and titrate against 0.01N EDTA till the color changes from wine red to blue. This titre value represents both $\mathrm{Ca}$ and $\mathrm{Mg}$. If you deduct the $\mathrm{Ca}$ titer value, you get the titre value of $\mathrm{Mg}$.

\subsubsection{Determination of Sulphur in plant sample}

Sulphur is estimated in plant sample by a method called turbidimetry method. The Sulphur content in the solution is precipitated by Barium ions as Barium sulphate (which develops turbidity). This turbidity is measured by turbidity meter or colorimeter which is proportional to the amount of Sulphur present in the sample.

Pipette out $10 \mathrm{~mL}$ of aliquot plant digest in to conical flask. Add $1 \mathrm{~mL}$ of $6 \mathrm{~N} \mathrm{HCl}$ and $1 \mathrm{~mL}$ of gum acacia and mix well. Then add about $0.5 \mathrm{~g}$ of Barium chloride and keep for a minute and swirl gently and read the absorbance. 


\subsubsection{Determination of Iron, Manganese, Zinc \& Copper in plant sample}

These four elements are estimated by using atomic absorption spectrophotometer. The atomic absorption spectrophotometer is based on the principle that when the atoms of metallic elements are introduced into a flame, a large percentage of metal atoms will remain in the non-emitting ground state and are receptive of light radiation of their own specific resonance wavelength. The absorption of radiation is proportional to the concentration of the atoms of that element present in the solution.

Dissolve 7.022g of A.R Ammonium ferrous sulphate in $400 \mathrm{~mL}$ of deionised water and add $5 \mathrm{~mL}$ of concentrated $\mathrm{H}_{2} \mathrm{SO}_{4}$ and make up the volume to $1 \mathrm{Lt}$ which gives $1000 \mathrm{ppm}$ Iron. From this, prepare $100 \mathrm{ppm}$ Iron solution by taking $10 \mathrm{~mL}$ into $100 \mathrm{~mL}$ volumetric flask and make up the volume. By preparing 5, 10, 15, 20 \& $25 \mathrm{ppm}$ Iron solution and feeding to atomic absorption spectrophotometer, we can get standard curve in the instrument. Further by feeding sample digest, we can estimate the Iron content present in the sample.

\section{Estimation of Manganese}

Dissolve 3.076g of Manganese sulphate in double distilled water and make up to 1Lt to get 1000 ppm of Manganese. $10 \mathrm{~mL}$ of this solution is diluted to $100 \mathrm{~mL}$ to get a solution of $100 \mathrm{ppm}$ of Manganese. From this we can prepare 5, 10, 15, 20 and $25 \mathrm{ppm}$ of Manganese solution for standard curve. After feeding the standards, we can feed the samples and get the readings.

\section{Estimation of Zinc}

The procedure is similar to Iron and Manganese but standard solution should be prepared separately.

Standard solution: dissolve 4.398g of AR Zinc Sulphate in distilled water and make up to $1000 \mathrm{~mL}$ which gives 1000 ppm Zinc solution. $10 \mathrm{~mL}$ of this solution is diluted to $100 \mathrm{~mL}$ to get $100 \mathrm{ppm}$ solution of Zinc. From this solution we can prepare 5, 10, 15, $20 \& 25 \mathrm{ppm}$ of Zinc solution for the standard curve. After feeding the standards, we can feed the samples for getting the readings.

\section{Estimation of Copper}

Standard solution preparation: dissolve 3.929g of AR Copper Sulphate in distilled water and make up to 1Lt which gives $1000 \mathrm{ppm}$ of Copper solution. $10 \mathrm{~mL}$ of this solution is diluted to $100 \mathrm{~mL}$ to get $100 \mathrm{ppm}$ of Copper solution. From this solution, you can prepare 5, 10, 15, $20 \& 25 \mathrm{ppm}$ of Copper solution for standard curve preparation. After that standards are fed and the readings are recorded [5].

\section{Results}

\subsection{Improved crop response in Phaseolus aureus}

Chemically treated seeds of Green gram (Phaseolus aureus) were sown in the plots with and without GOT shows the number of pods in the plant.

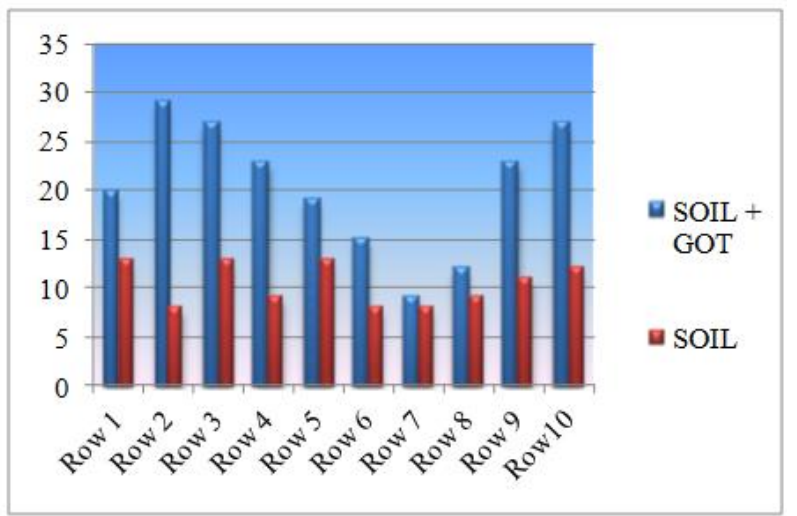

Fig. 4: Graph representing the growth rate of Phaseolus aureus 


\subsection{Study of root nodules in Phaseolus aureus}

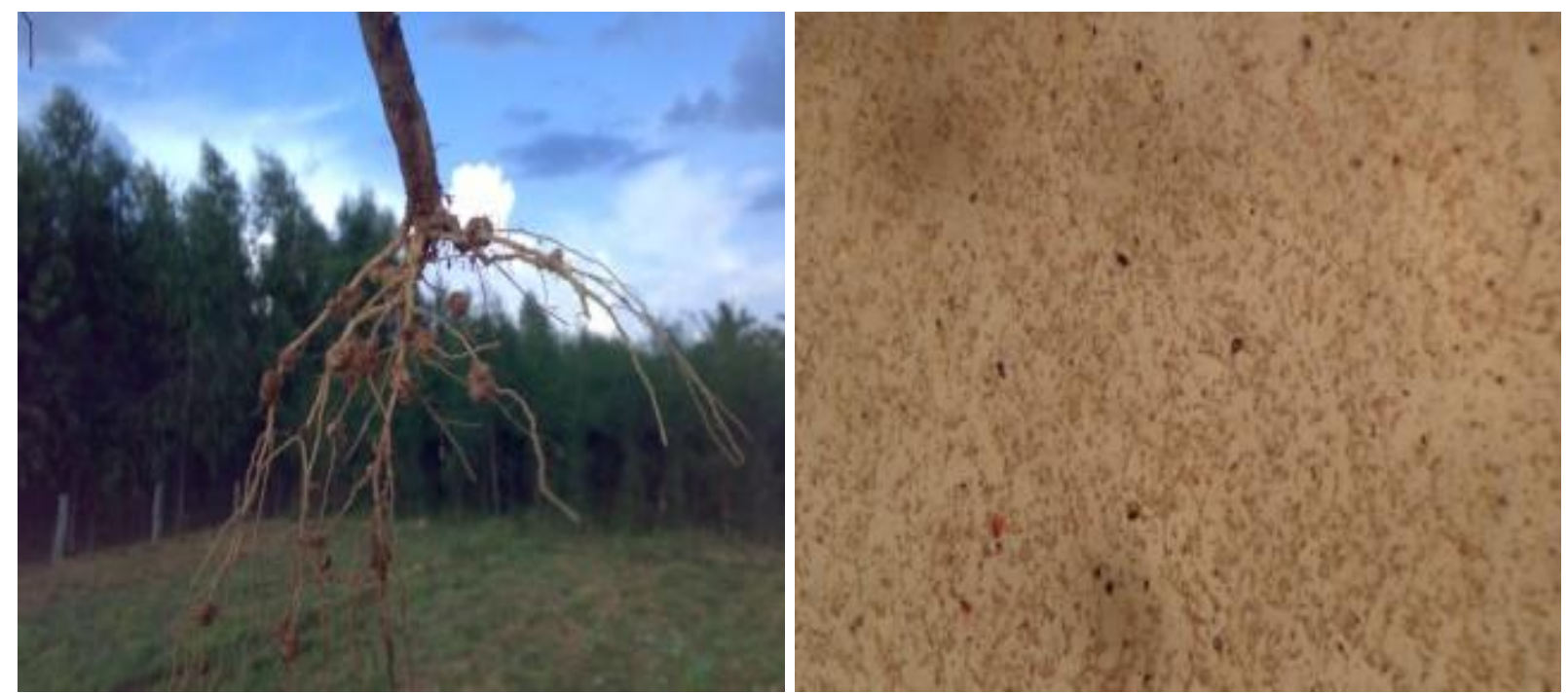

Fig. 5: Plaseolus aureus grown with SOIL+GOT, Microscopic view shows increase in number of root nodules and maximum rhizobium activity
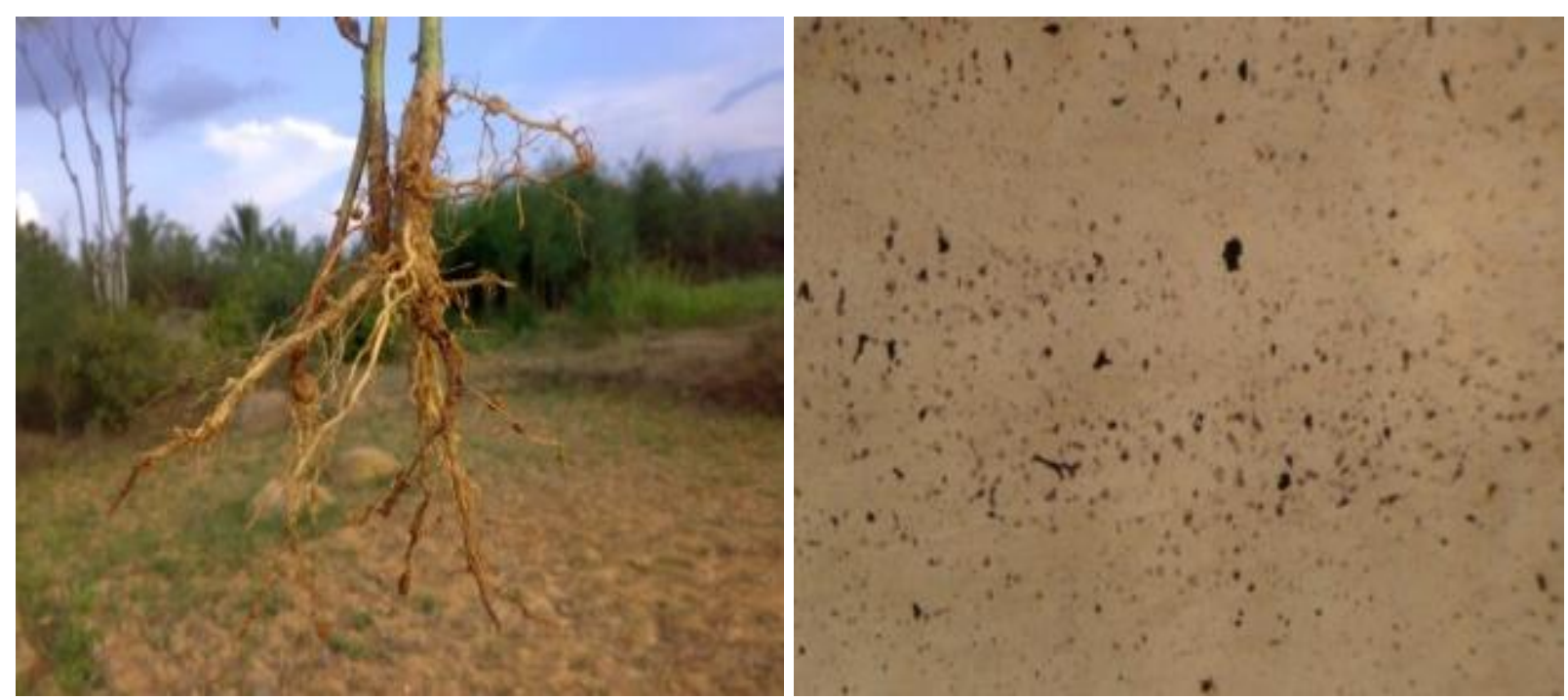

Fig. 6: Plaseolus aureus grown with SOIL, Microscopic view shows less number of root nodules and minimum rhizobium activity

\subsection{Estimation of proteins in Phaseolus aureus grown with SOIL+GOT by Lowry's method}

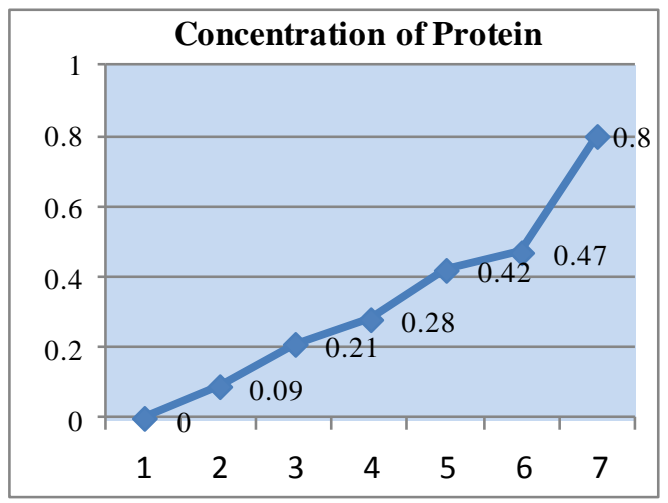

Fig. 7: Graph representing the concentration of proteins in Phaseolus aureus 


\subsection{Improved crop response in Brassica oleracea botrytis}

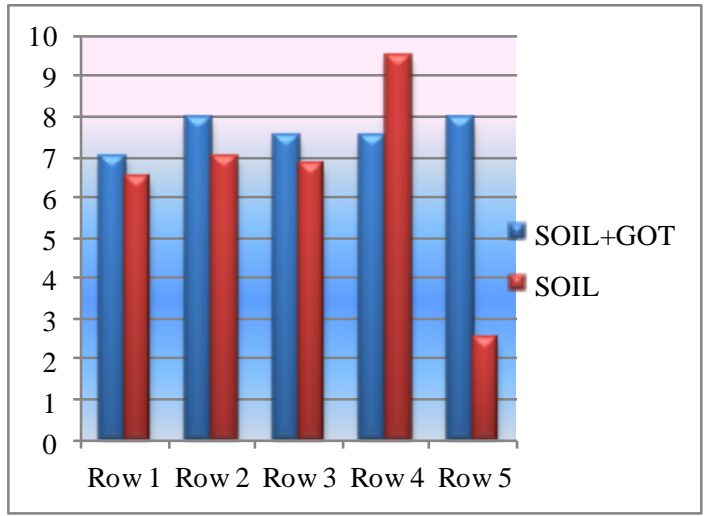

Fig. 8: Graph representing the growth rate of flower size $(\mathrm{mm})$ in Brassica oleracea botrytis

\subsection{Improved crop response in Brassica oleracea capitata}

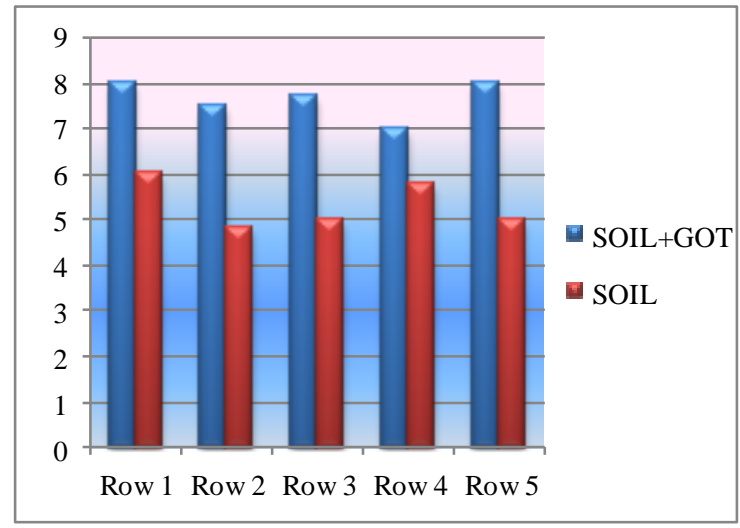

Fig. 9: Graph representing the growth rate of flower size (mm) in Brassica oleracea capitata

\subsection{Chemical analysis of plantation water}

\begin{tabular}{cccc}
\hline Sl. no & Parameters & $\begin{array}{c}\text { Drinking water limits as per } \\
\text { ISO: } 10599 / 1991\end{array}$ & Results \\
\hline 1. & & $<05.00 \mathrm{Hazen}$ & 01.25 \\
2. & Color & $<05.00 \mathrm{NTU}$ & 02.51 \\
3. & Turbidity & $06.50-08.50$ & 07.29 \\
4. & pH value & $<1000.00 \mathrm{ppm}$ & 450.00 \\
5. & Total dissolved salts & $<200.00 \mathrm{ppm}$ & 03.58 \\
6. & Phenolphthalein alkanity as $\mathrm{CaCO}_{3}$ & $<200.00 \mathrm{ppm}$ & 160.80 \\
7. & Total alkalinity as $\mathrm{CaCO}_{3}$ & $<300.00 \mathrm{ppm}$ & 221.98 \\
8. & Total hardness as CaCO & 24.25 \\
9. & Calcium & $<75.00 \mathrm{ppm}$ & 06.14 \\
10. & Magnesium & $<30.00 \mathrm{ppm}$ & 43.58 \\
11. & Sodium & $\mathrm{N} . \mathrm{S}$ & 00.030 \\
12. & Iron & $<00.30 \mathrm{ppm}$ & 48.19 \\
13. & Chlorides & $<200.00 \mathrm{ppm}$ & 19.20 \\
14. & Sulphates & $<45.00 \mathrm{ppm}$ & 07.38 \\
15. & Nitrates & $<04.80 \mathrm{ppm}$ & 01.74 \\
16. & Ammonium & $<01.50 \mathrm{ppm}$ & 00.31 \\
17. & Fluoride & & 15.90 \\
18. & Silica & $\mathrm{N} . \mathrm{S}$. & 790.00 \\
\hline
\end{tabular}




\subsection{Analysis of Gold Ore Tailings (GOT)}

\begin{tabular}{ccc}
\hline Analytical tests & Control (GOT) & Standard recommended by IIHR \\
\hline $\mathrm{pH}$ & 7.57 & $6.30-7.50$ \\
EC (dsm $\left.{ }^{-1}\right)$ & 2.895 & $0.75-1.00$ \\
Organic Carbon $(\%)^{\text {Nitrogen }(\mathrm{ppm})}$ & 0.42 & $125-250$ \\
Phosphorus (ppm) & 68 & $30-50$ \\
Potassium (ppm) & 77 & $150-300$ \\
Calcium (ppm) & 897 & $1000-1500$ \\
Magnesium (ppm) & 2682 & $180-250$ \\
Sulphur (ppm) & 163 & $15-25$ \\
Iron (ppm) & 180.0 & $5-10$ \\
Manganese (ppm) & 13.6 & $3-10$ \\
Zinc (ppm) & 8.2 & $1.0-1.50$ \\
Copper (ppm) & 6.6 & $0.5-1.0$ \\
\hline
\end{tabular}

\subsection{Chemical analysis of Brassica oleracea capitata and Brassica oleracea botrytis}

\begin{tabular}{ccccc}
\hline Detail & $\begin{array}{c}\text { Br.ole. capitata } \\
\text { (Soil) }\end{array}$ & $\begin{array}{c}\text { Br.ole.capitata } \\
\text { (Soil + GOT) }\end{array}$ & $\begin{array}{c}\text { Br.ole. botrytis } \\
\text { (Soil) }\end{array}$ & $\begin{array}{c}\text { Br.ole.botrytis } \\
\text { (Soil + GOT) }\end{array}$ \\
\hline N\% & 2.24 & 2.41 & 2.94 & 2.83 \\
P\% & 0.127 & 0.127 & 0.181 & 0.207 \\
K\% & 2.20 & 2.40 & 3.00 & 2.80 \\
Ca\% & 0.92 & 0.84 & 0.68 & 0.48 \\
Mg\% & 0.27 & 0.26 & 0.31 & 0.22 \\
S\% & 0.375 & 0.382 & 0.377 & 0.370 \\
Fe ppm & 59 & 54 & 71 & 98 \\
Mn ppm & 14 & 13 & 19 & 21 \\
Zn ppm & 16.9 & 17.5 & 32.0 & 31.0 \\
Cu ppm & 4.2 & 5.0 & 5.9 & 6.5 \\
\hline
\end{tabular}

\section{Discussion}

Around 2000 tons of GOT is dumped every day and it has become very difficult for the safe disposal. Implementation of Gold Ore Tailings in cultivation would help as manure for plants. The Phaseolus aureus grown in research field was subjected to protein estimation by Lowry's method where the Phaseolus aureus grown with Soil + GOT shows maximum protein concentration when compared with Phaseolus aureus grown only with Soil. Root nodules of Phaseolus aureus grown with Soil + GOT has shown higher percentage of Nitrogen Fixation as the presence of Rhizobium bacteria is more when compared to the Phaseolus aureus grown with Soil in absence of GOT.

A comparative study between the Soil sample and the crop i.e. Phaseolus aureus grown with Soil + GOT shows maximum growth by absorbing nutrients like Nitrogen, Phosphorus, Magnesium, Potassium, Manganese, Iron rather than Calcium, Zinc \& Copper. From this study we came to know that there was $30 \%$ increase in the yield with respect to Phaseolus aureus.

The comparative study done between the Soil sample and the crop i.e. Brassica oleracea botrytis grown with Soil + GOT shows maximum growth by absorbing nutrients like Phosphorus, Magnesium, Iron, rather than Nitrogen, Calcium, Sulphur, Zinc, Manganese, Potassium, Copper.

A comparative study between the Soil sample and the crop i.e. Brassica oleracea capitata grown with Soil + GOT shows maximum growth by absorbing nutrients like Nitrogen, Phosphorus, Calcium, Magnesium, Sulphur, Manganese \& Zinc rather than Potassium, Iron and Copper.

When a comparison made between the Brassica oleracea capitata grown only in Soil and that of GOT mixed soil revealed the fact that minerals such as Nitrogen, Potassium, Sulphur, Zinc and Copper showed an increase trend in Brassica oleracea capitata grown in GOT mixed soil, but the influence of GOT was negligible in case of minerals such as Phosphorus, Calcium and Magnesium. GOT has shown suppressive effect in case of Iron and Manganese up taken by plant. 
When a comparison was done between Brassica oleracea botrytis grown only in Soil and that in GOT mixed soil revealed that Nitrogen, Potassium, Calcium, Magnesium and Sulphur showed a decreasing trend in Brassica oleracea botrytis grown in GOT mixed soil. But minerals such as Phosphorus, Iron and Manganese showed an increasing trend in case of Brassica oleracea botrytis grown in GOT mixed soil. Whereas the influence of GOT was negligible in case of minerals such as Zinc and Copper when compared to pure soil. This results shows that the crops grown with Soil + GOT enhanced the maximum growth and maximum absorption of minerals from both soil and GOT.

\section{Summary}

GOT can be used to blend either the manure or the fertilizer in agriculture and saves investment on the use of fertilizers. Implementation of GOT increases the yield and decreases the duration of the harvesting time. GOT provides the best solution to dispose enormous quantities of readily available mining waste (GOT) dumped unused for decades. The vast land used to dump such mining waste can be reclaimed. Poor farmers, who cannot afford expensive Phosphatic fertilizers, can use such mining waste as a source of Phosphate. If all the GOT dumped in the gold mine is processed not only one can recover precious metal but also the land can be reclaimed beside the protection of the environment. The Processed GOT can be made available to farmers almost at no cost to be used for agriculture, after all agriculture industry is the backbone of any nation!

\section{Acknowledgement}

Authors thank all the faculty members of Hutti Gold Mines Ltd (HGML) Raichur, for motivating and encouraging our research strategies by providing Gold Ore Tailings (GOT) as the raw material.

Authors would like to thank Principal, Staff members of Department of Botany and Biotechnology K.L.E's S. Nijalingappa College, Rajajinagar, Bangalore for their encouragement throughout this research work and also funding this project. Our sincere thanks to the faculty members of Department of Soil science of Indian Institute of Horticultural Research (IIHR), Hessaragatta, Bangalore, for getting us the soil and vegetable samples analyzed in their labs and sharing their vast knowledge and experience with us.

Authors copiously thank Mr. M Somashekar and also for helping us during the harvesting season of the crop cultivation and also for frequent transportation arrangement from Bangalore to the place where the research was carried out.

\section{References}

[1] S. Sadasivam and A. Manickam Biochemical methods 2nd edition, India, 2009.

[2] Frank B Salisbury and Cleon W Ross. Plant physiology, 4th edition, India, 2008.

[3] Michael .J. Pelczar, Chan and Noel R. Krieg, Microbiology, 5th edition, Newyork, 2008.

[4] Sandhana, Karnataka Flora, 2nd edition, India, 2008.

[5] Basic Techniques and Analytical methods involved in Soil, Leaf Analysis and Instrumentation by IIHR, India, 2008.

[6] Use of mine ore waste as a source of micronutrient in the crop production by University of Agricultural sciences. India, 2008.

[7] FCCI Environment Conclave "Creating markets for sustainable waste management", India 2008

[8] Vidyavathi, KK Math, G.S Dasog, Influence of Gold Old Tailings on yield and uptake of nutrients by a groundnut crop in a vertisol, Karnataka J. Agric. Sci., 21(2): (277-279) 2008.

[9] Manjunath, Use of Copper Ore Tailings in agriculture, University of Agricultural Sciences, 1st edition, Dharwad, India, 2008. 